consortium should be empowered to implement any proposals falling within the powers of the authorities constituting it; to encourage and facilitate appropriate action by other bodies; and to develop support among other bodies and the general public for the policies and measures proposed. It should maintain close working liaison between the interests concerned and create new facilities for the public enjoyment of Broadland within the strategy of the Conservancy's Report, as well as maintain constant review of trends and developments in the area and initiate action to obtain data on them. It should also detect and appraise gaps in the powers required to implement fully the agreed policies, and advise on the economic implications of these proposals.

\title{
RADIOCHEMICALS
}

$\mathrm{H}$ UR booklets have recently been issued by the Radio. chemical Centre, Amersham*.

The first, Selected References to Tracer Techniques, is a revised edition and contains a bibliography of selected publications useful to newcomers to tracer work. The contents consist of titles of general texts and articles dealing with the preparation of labelled compounds, tracer applications, methods of measurement and safety precautions.

Radioactive Isotope Dilution Analysis is a second edition of the booklet in which the principle of the analysis is explained and shown to be a sensitive method of determ. ination of many substances in mixtures. It is emphasized that the technique does not require expensive laboratory facilities or materials. The application of the method is illustrated by particular examples.

Problenas of radiation self-decomposition of materials are of increasing interest to users of radioactive tracer compounds, and the summary of experience gained from the storage of radioactive compounds at the Radiochemical Centre which is given in the third booklet, The Stability of Labelled Organic Compounds, should be very helpful. The information is largely empirical. Data for a number of compounds are listed. The essential factors in the investigation or observation of the decomposition from selfirradiation are the chemical character of the molecule which determines the liability to primary (external) and secondary effects; the purity, the solvents and diluents, the concentration, the specific activity, the temperature and other environmental conditions; and the type and

* The Radiochemical Centre. Selected References to Tracer Techniques. Revised edition. Pp. 12. Radioactive Isotope Dilution Analysis. Second Edition. Pp. 12. The Stability of Labelled Organic Compounds. Pp. 14 Standards of Activity. By G. R. Newbery et al. Pp. 27. (Amersham; The Radiochemical Centre, 1965.) energy of the radiation from the incorporated nuclide. A detailed list of precautions in handling or storing radioactive organic compounds is included.

The fourth and most recent booklet, Standards of Activ. ity, discusses the types of standard available, their certification and use. The activity of a quantity of radioactive material is defined in accordance with the 1962 report of the National Commission on Radiological Units and Measurements (ICRU) (NBS Handbook 86) as the number of nuclear disintegrations which occur in the quantity in unit time. The curie, $5.7 \times 10^{10}$ disintegrations per sec, is the special unit of activity, and activity can be quoted in curies or in its sub-multiples. Activity is not constant with time but decays at a rate determined by the radionuclides present.

Because of uncertainties in purity and half-life, the accuracy to which the activity can be calculated at a given time becomes worse the longer the period from the reference time. Standards of activity have therefore an ephemeral nature and care must be taken in the interpretation of the title 'standard'. The most satisfactory physical form for a standard of activity is a solution in a flame-sealed glass ampoule, but other forms are available. Standards of activity are principally used for the calibration of measuring instruments, and the booklet makes clear the precautions to be taken if full use is to be made of the high accuracy associated with absolutely standardized solutions. In the second half of the booklet the standards available from the Radiochemical Centre are discussed and a complete schedule (operative during 196566) of standardized solutions together with details of their guaranteed accuracy and delivery time is given. Each of the four booklets contains a list of references.

S. WeINTRoub

\section{SCIENCE ABSTRACTS}

$\mathrm{M}^{\mathrm{s}}$ EMBERS of the Documentation Research Project section of the American Institute of Physics have carried out a comprehensive survey of published physics literature by a detailed analysis of the contents of the 1961 issues of Physics Abstracts (Section $A$ of Science Abstracts). A report of the survey has recently been published*. A total of 20,287 abstracts covering 405 periodicals from 29 countries were scrutinized, and certain details coded and transfered into machine-readable form. The method of coding used is described and illustrated by a code sheet and sample abstract. The specific codes chosen for the country of origin, the periodical, the language and the subject fields, which formed the four major fields of enquiry, are included in an appendix to the report. Each field is dealt with in detail in a separate section of the report. The greater number of papers were devoted to nuclear physics and solid-state physics. About half the articles abstracted during 1961 had been published

* The Journal Literature of Physics: a Comprehensive Study based on Physics Abstracts (Science Abstracts, Section A), 1961 I88ues. By Stella Keenan and Pauline Atherton. Pp. 156. (New York: The American Insti-
tute of Physics, 1964.) during that year. This may be closely related to the fact that Physics Abstracts uses the author abstract when available. There were twice as many author abstracts as signed abstracts. Incorporated in the report, in addition to the numerous tables of data and illustrative charts, is a reprint of an article in the Journal of Chemical Documentation $(4,157$; July 1964), in which a description is given of an investigation of the time-lag of coverage by Physics Abstracts with respect to three particular periodicals. The time-lag refers to the time in months between the date of issuo of the periodical in which an article appeared and the date of appearance of its abstract in Physics Abstracts. The three periodicals were Physical Review Letters (an English language journal with no author abstracts), the Journal of Chemical Physics (an English language journal with author abstracts for articles but not for Letters to the Editor), and Zeitschrift für Physik (a foreign language journal with author abstracts in English or in a foreign language). The investigation showed that the average time-lag was similar for all three periodicals, about three to four months. Many factors contributed 